九州大学学術情報リポジトリ

Kyushu University Institutional Repository

\title{
Plastic deformation and allotropic phase transformations in zirconia ceramics during high-pressure torsion
}

\section{Edalati, Kaveh}

Department of Materials Science and Engineering, Faculty of Engineering, Kyushu University I WPI, International Institute for Carbon-Neutral Energy Research (I2CNER), Kyushu University

Toh, Shoichi

Research Laboratory for High Voltage Electron Microscopy, Kyushu University

Ikoma, Yoshifumi

Department of Materials Science and Engineering, Faculty of Engineering, Kyushu University

Horita, Zenj i

WPI, International Institute for Carbon-Neutral Energy Research (I2CNER), Kyushu University I

Department of Materials Science and Engineering, Faculty of Engineering, Kyushu University

http://hdl. handle. net/2324/26377

出版情報: Scripta Materialia. 65 (11)，pp.974-977，2011-11. Elsevier バージョン：

権利関係 : (C) 2011 Acta Materialia Inc. 
Scripta Materialia 65 (2011) 974-977

Received 1 August 2011; Revised 24 August 2011; Accepted 25 August 2011

Available online 31 August 2011

\title{
Plastic deformation and allotropic phase transformations in zirconia ceramics during high-pressure torsion
}

\author{
Kaveh Edalati, ${ }^{a, b, *}$ Shoichi Toh, ${ }^{\mathrm{c}}{ }^{\text {Yoshifumi Ikoma }}{ }^{\mathrm{a}}$ and Zenji Horita ${ }^{\mathrm{a}, \mathrm{b}}$ \\ ${ }^{a}$ Department of Materials Science and Engineering, Faculty of Engineering, Kyushu University, \\ Fukuoka 819-0395, Japan \\ ${ }^{\mathrm{b}}$ WPI, International Institute for Carbon-Neutral Energy Research (I2CNER), Kyushu University, \\ Fukuoka 819-0395, Japan \\ c Research Laboratory for High Voltage Electron Microscopy, Kyushu University, Fukuoka \\ 819-0395, Japan
}

\begin{abstract}
Severe plastic deformation using high-pressure torsion (HPT) is successfully applied at room temperature to partially stabilized $\mathrm{ZrO}_{2}$. X-ray diffraction and Raman spectroscopy analyses reveal that appreciable strain is introduced in the sample and a phase transformation with a coherent interface occurs from the metastable tetragonal phase to the monoclinic phase during HPT. The fraction of the stress-induced monoclinic phase increases with straining, reaches a saturation level. Transmission electron microscopy shows that nanograins of high dislocation density but with no twins are formed during HPT.
\end{abstract}

Keywords: Zirconia; High-pressure torsion; Severe plastic deformation (SPD); Ceramics; Phase transformations.

\footnotetext{
* Corresponding author at: Department of Materials Science and Engineering, Faculty of Engineering, Kyushu University, Fukuoka 819-0395, Japan. Tel./fax: +81 92802 2992; e-mail: kaveh.edalati@zaiko6.zaiko.kyushu-u.ac.jp.
} 
Ceramics are generally brittle materials at room temperature. This is a consequence of strong ionic or covalent bonds, which make the movement of dislocations through the crystalline structure difficult [1]. So far, partial plasticity at room temperature has been reported for microscopic ceramic samples [2,3] and for specific loading conditions, such as high-pressure compression [4-6] and indentation [7]. It is believed that significant ductility can be achieved in ceramics only at high temperatures when diffusion-controlled deformation mechanisms become active [1]. In this work, intense plastic deformation is imposed in partially stabilized $\mathrm{ZrO}_{2}$ at room temperature by torsional straining under high hydrostatic pressure; this process is known as high-pressure torsion (HPT) [8].

The HPT process was first invented by Bridgman in 1935 [9]. In this process, a thin disc specimen is placed between two anvils under high pressure and shear strain is introduced by rotating the two anvils with respect to each other. The shear strain $\gamma$ is given by $[10,11]$

$$
\varepsilon=\frac{2 \pi r N}{t}
$$

where $r$ is the distance from the disc center, $N$ is the number of revolutions and $t$ is the thickness of disc.

There are several review papers [10,11] and numerous reports of HPT processing of different metallic materials (e.g. [12-15]), semi-metals (e.g. [16,17]), intermetallics (e.g. [18,19]) and amorphous materials (e.g. [20,21]), whereas there is only one report for ceramics [22]. Following HPT, severe plastic deformation is introduced and the final grain size, which is a characteristic of each material, usually reaches the submicrometer level in metallic materials [10-15] and the nanometer level in semi-metals and intermetallics [16-19]. Partial amorphization in intermetallics [18], partial nonocrystallization in amorphous materials [21], consolidation of amorphous materials [20,21], partial consolidation of ceramic powders [22] and phase transformations in several materials, including Ti [23,24], Zr [25,26] and TiNi [18], have been reported when processed by HPT. To date, there has been no investigation carried out to understand the effect of plastic deformation on microstructural evolution and phase transformations in ceramics during HPT at room temperature. In this study, $\mathrm{ZrO}_{2}$ is processed by HPT to understand the structural response to loading. Raman spectroscopy and X-ray diffraction (XRD) analyses as well as microstructural examinations using transmission electron microscopy (TEM) are used for investigation.

It is known that $\mathrm{ZrO}_{2}$ has a monoclinic phase at room temperature under ambient pressure, and transforms to a tetragonal phase at $1373 \mathrm{~K}$, a cubic phase at $2673 \mathrm{~K}$, a liquid phase at $2963 \mathrm{~K}$ and an orthorhombic phase under pressures above $10 \mathrm{GPa}$ [27]. However, addition of specific elements such as $\mathrm{Y}$ to $\mathrm{ZrO}_{2}$ stabilizes the tetragonal phase at room temperature [28]. This partially stabilized $\mathrm{ZrO}_{2}$ exhibits a phase transformation from tetragonal to monoclinic [29]. Although this phase transformation is stress induced [26], the strain component may influence the phase transformation $[3,30]$.

The material used in this study was commercially available partially stabilized $\mathrm{ZrO}_{2}$ powder with 3 mol. $\% \mathrm{Y}_{2} \mathrm{O}_{3}$, having 24\% monoclinic phase and 76\% tetragonal phase, with 50 $\mu \mathrm{m}$ particle size. The HPT facility consisted of upper and lower anvils, each having a flat-bottomed shallow 
hole, $10 \mathrm{~mm}$ in diameter and $0.25 \mathrm{~mm}$ in depth, at the center. The details concerning the HPT facility have been reported elsewhere [26]. Approximately $0.7 \mathrm{~g}$ of the powders was put in the hole located at the center of the lower anvil. The powders were first compressed by lifting the lower anvil against the upper anvil, then both anvils were rotated with respect to each other while pressing. The HPT operation was conducted at room temperature with a rotation speed of $\omega=1.0 \mathrm{rpm}$ for either $N=0,0.25,1,2$, 4 or 10 revolutions under a pressure of $P=6 \mathrm{GPa}$.

After processing by HPT, the discs were polished and Raman spectroscopy was performed using a micro-Raman system in backscattering geometry with a $488 \mathrm{~nm}$ argon ion laser excitation focused on an $\sim 1 \mu \mathrm{m}$ diameter spot $3.5 \mathrm{~mm}$ from the disc center. Second, structural analyses with XRD were performed using $\mathrm{Cu} K \alpha$ radiation at $40 \mathrm{kV}$ and $40 \mathrm{~mA}$ with a scanning step of $0.02^{\circ}$ and a scanning speed of $0.5^{\circ} . \mathrm{min}^{-1}$. Third, for the TEM, small amounts of sample were removed from the positions $3.5 \mathrm{~mm}$ away from the center and added to ethanol to make a suspended solution. A carbon-type grid was dipped into the solution for $5 \mathrm{~s}$ and dried in air before TEM. The transmission electron microscope was operated at $300 \mathrm{kV}$ for microstructural observations.

Raman spectra of the sample after application of a pressure of $6 \mathrm{GPa}$ but without rotation $(N=$ 0 ) and of the samples processed by HPT for different numbers of revolutions $(N=0.25,1,2$ and 10), including the as-received powder, are shown in Figure 1(a). Details of the Raman spectrum of zirconia have been reported elsewhere [32]. The peak heights corresponding to the tetragonal phase become less visible with increasing number of revolutions. The XRD analysis, shown in Figure 1(b), confirms the same phase transformation. The (101) tetragonal peak becomes less pronounced while the several monoclinic peaks become more prominent with increasing numbers of revolutions. Figure 1 clearly shows that, although stress components are substantial in triggering the phase transformation [30,31], the formation of the stress-induced monoclinic phase is facilitated with plastic straining. This is consistent with earlier reports concerning the effect of strain on pressure-induced $\mathrm{x}$-phase formation in $\mathrm{Ti}[23,24]$ and $\mathrm{Zr}[25,26]$.

The XRD spectra shown in Figure 1(b) are evaluated quantitatively and the results are shown in Figure 2(a) and (b), where the fraction of the monoclinic phase and the full width at half maximum (FWHM) of the tetragonal (101) plane and of the monoclinic ( $\overline{1} 11)$ plane are plotted against the imposed shear strain. Here, the monoclinic-phase fraction was calculated by considering the intensities of FWHM monoclinic ( $\overline{1} 11)$ and (111) peaks and the intensities of FWHM tetragonal (101) peak using the equation given in Ref. [33]. The following three important aspects are obtained from Figure 2.

First, the fraction of monoclinic phase increases slightly, from $24 \%$ to $30 \%$, after application of the pressure, but increases significantly with the torsional straining. The fraction increases gradually with strain and levels off at $76 \%$ after $\mathrm{N}=10$ revolutions. The FWHM also increases strongly with torsional straining and levels off and increases gradually at large strains, respectively. The peak broadening that results from lattice strains and grain fragmentation is important evidence proving the occurrence of permanent plastic deformation during the HPT processing.

Second, the peak broadening is more significant for the tetragonal phase than for the monoclinic phase, indicating that plastic strain is introduced more easily in the tetragonal phase. 
This is reasonable, as the tetragonal phase is known to be more ductile than the monoclinic phase [28].

Third, the tendency of data points in Figure 2 is to saturate to the steady states at large strains; this is very similar to those in metallic materials $[11,26]$. The steady state, which appears even in very soft materials such as high-purity Al [12,34], does not imply that the introduction of plastic strain is limited. The steady state, however, appears not only by a balance between the formation and annihilation of the lattice defects $[10,11,35]$ but also by a balance between the formation and destruction of the transformed phase [26] occurring during the processing. The variation in the fraction of monoclinic phase with straining is similar to that in the fraction of $\mathrm{x}$ phase in $\mathrm{Zr}$ with straining [26].

(a)

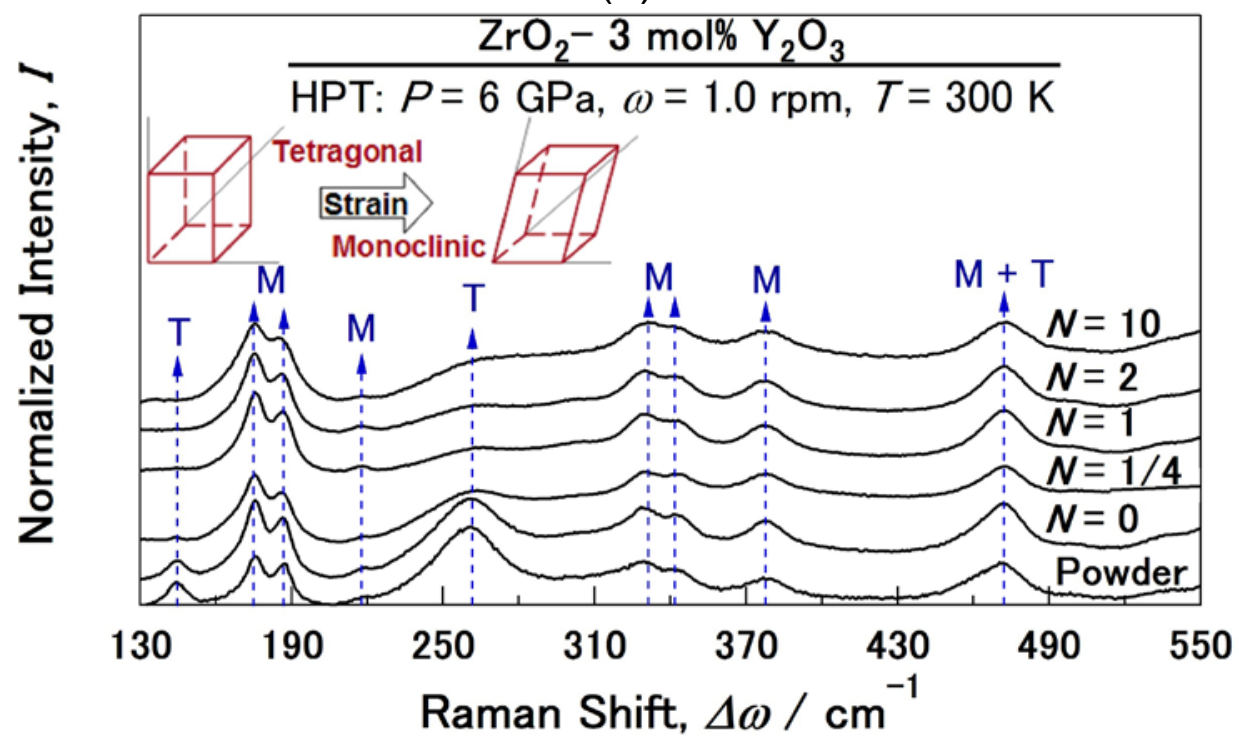

(b)

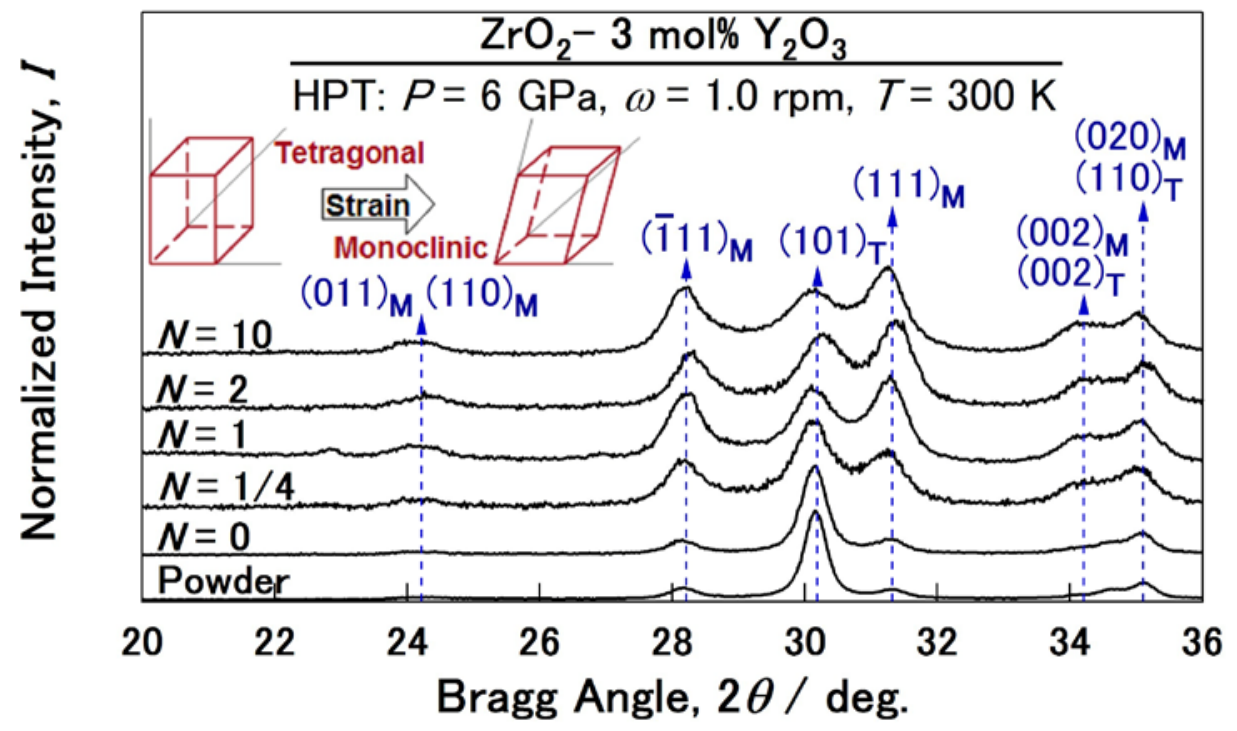

Figure 1. (a) Raman spectra and (b) XRD profiles for samples processed for $\mathrm{N}=0-10$ revolutions, including as-received powders. $\mathrm{T}$ and $\mathrm{M}$ indicate peaks corresponding to tetragonal and monoclinic phases, respectively. 


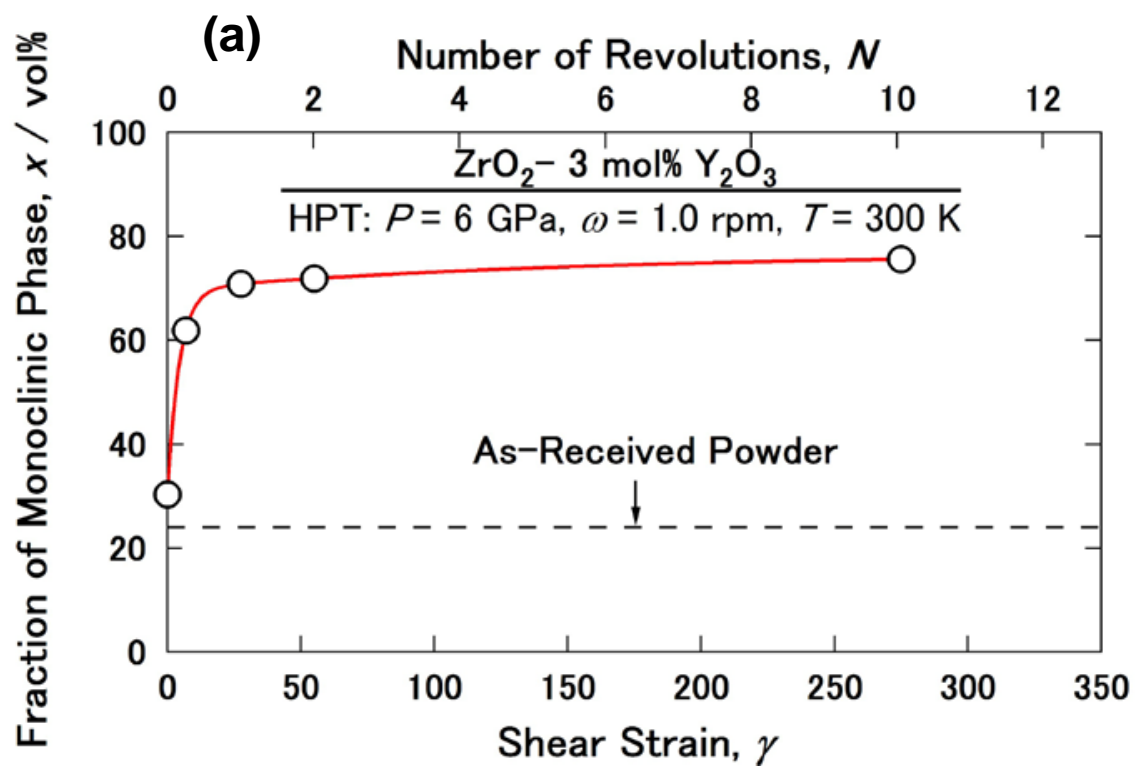

(b)

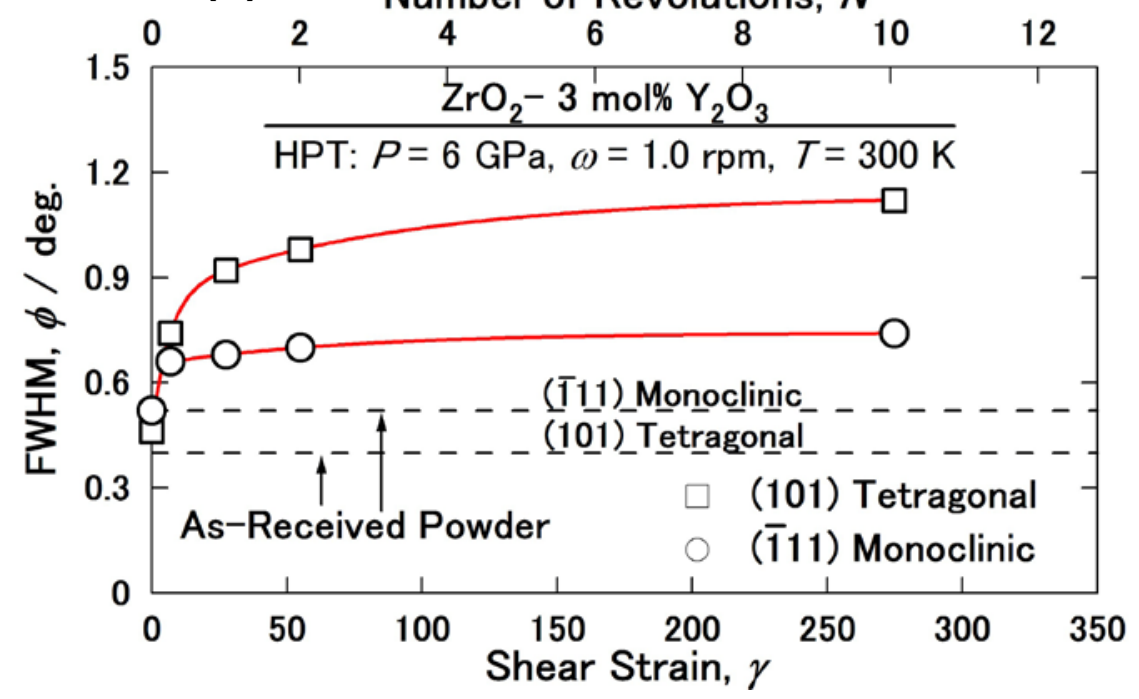

Figure 2. XRD quantitative results for samples processed for $\mathrm{N}=0-10$ revolutions, including as-received powders. Variations of (a) the fraction of monoclinic phase and (b) the FWHM for tetragonal and monoclinic phases plotted against shear strain and number of revolutions.

The TEM results of the steady-state regime are shown in Figure 3 for samples after $N=10$ revolutions, where (a) is a high-resolution image, (b) is a lattice image enlarged from the square region in (a), and (c-e) are diffractograms obtained by fast Fourier transform (FFT) analyses of the regions indicated by $A, B$ and $C$, respectively, in (b). The diffractograms shown in Figure 3(c-e) indicate that regions $\mathrm{A}, \mathrm{B}$ and $\mathrm{C}$ in Figure $3(\mathrm{~b})$ correspond to the monoclinic, tetragonal and monoclinic phases, respectively.

Several important points are derived from Figure 3. First, it is apparent from Figure 3(a) that the microstructure of the steady state consists of nanograins with an average grain size of $25 \mathrm{~nm}$, obtained by measuring 20 grains. It is well known that the final grain size after processing with HPT is characteristic for each material and is reasonably independent of the initial state of the 
material [35]. Therefore, being analogous to semimetals [16,17] and intermetallics [18,19], the final grain sizes after HPT are at the nanometer level in ceramics. This could be because of the similarities in having strong covalent or ionic atomic bondings.

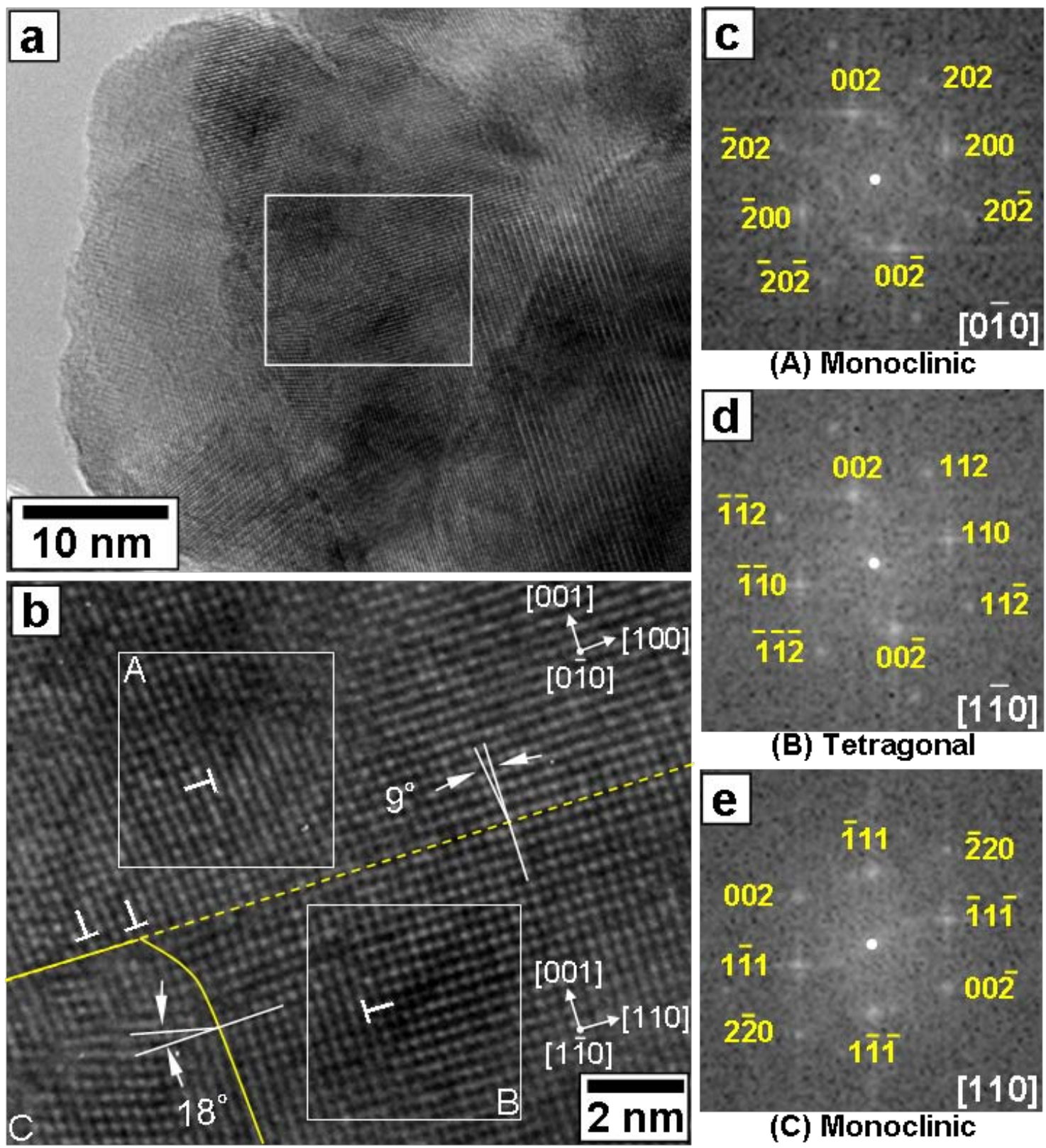

Figure 3. TEM results for sample processed for $N=10$. (a) High-resolution image; (b) lattice image enlarged from square region in (a); (c-e) FFT analyses of regions A, B and C in (b), which correspond to monoclinic, tetragonal and monoclinic phases, respectively. In (b), the $\mathrm{T}$ marks represent dislocations, the dotted line represents a coherent low-angle monoclinic/tetragonal interface and the solid curve represents a high-angle grain boundary.

Second, the close examination of the lattice image in Figure 3(b) reveals that there are several [001] and [100] dislocations (T marks) within the nanograins, with Burgers vectors of 0.13 and 0.09 $\mathrm{nm}$, respectively. The presence of such dislocations, which coincide with the lattice dislocation in partially stabilized zirconia, is consistent with the peak broadening observed in the XRD analysis as 
shown in Figures 1 and 2(b). An estimation of the dislocation density results in $4 \times 10^{16} \mathrm{~m}^{-2}$, provided that two dislocations are present in the view, as shown in Figure 3(b), and results in $2 \times 10^{15}$ $\mathrm{m}^{-2}$ provided that a single dislocation exists in one $25 \mathrm{~nm}$ nanograin, as obtained by the grain size measurement. Such dislocation densities are comparable to those in heavily rolled metallic materials and also in an HPT-processed Fe alloy [36]. It should be noted that only the dislocations with the Burgers vector perpendicular to the incident electron beam are visible in high-resolution TEM images.

Third, a coherent $\mathrm{A} / \mathrm{B}$ interface (dotted line) is present between the monoclinic and tetragonal phases in Figure 3(b). This suggests that a monoclinic nucleus forms with the coherent interface, consistent with earlier reports $[3,28]$.

Fourth, the presence of a B/C interface (solid line) between the monoclinic and tetragonal phases, which was at a high angle of misorientation, suggests that low-angle coherent interfaces develop to high-angle grain boundaries during straining. This is highly consistent with HPT processing of metallic materials [10,11,35].

Fifth, Figure 3(b) shows that the basal planes of the two phases are parallel as $(002)_{\mathrm{m}} / /(002)$, and the $(200)_{\mathrm{m}}$ plane is inclined to the $(110)_{\mathrm{t}}$ plane by $9^{\circ}$ due to an atomic shear to make the monoclinic b angle $99^{\circ}$.

Sixth, although the monoclinic phase usually contains twin structure [3,28,37], there are no or hardly any twins visible. This suggests that phase transformation might have proceeded with dislocation activity.

An earlier study unambiguously showed an appreciable peak broadening in XRD profiles for an HPT-processed $\mathrm{Al}_{2} \mathrm{O}_{3}$ without accompanying phase transformation [22]. Thus, plastic deformation by HPT is feasible not only in $\mathrm{ZrO}_{2}$ but also in other ceramics. The HPT process exerts high compressive pressures, which are sometimes even comparable to the ideal strength of the material. Therefore, the process suppresses the formation of cracks, retards stress concentration and brittle failure, and leads to overall compaction of the material during the torsional straining. These findings suggest that the HPT method is a good tool with which to investigate the plastic behavior of ceramic materials at room temperature, as well as a useful tool for production of nanograins in ceramics.

In summary, intense plastic strain was introduced in partially stabilized $\mathrm{ZrO}_{2}$ at room temperature using HPT. A stress-induced phase transformation occurred from the tetragonal phase to the monoclinic phase, while the total fraction of the monoclinic phase increased with straining, becoming saturated at a constant level at larger strain. Microstructural examination showed that the final grain size reached $\sim 25 \mathrm{~nm}$ and many dislocations were generated but no twins were visible within the nanograins during HPT processing.

We would like to thank Prof. Qixin Guo of Saga University for permitting us to use the Raman spectroscopy facility. K.E. thanks the Japan Society for Promotion of Science (JSPS) for a postdoctoral scholarship. This work was supported in part by a Grant-in-Aid for Scientific Research 
from the MEXT, Japan, in Innovative Areas "Bulk Nanostructured Metals”, and in part by Kyushu University Interdisciplinary Programs in Education and Projects in Research Development (P\&P).

[1] C. Barry Carter, M. Grant Norton, Ceramic Materials, Science and Engineering, Springer, New York, NY, 2007.

[2] W.W. Gerberich, J. Michler, W.M. Mook, R. Ghisleni, F. Ostlund, D.D. Stauffer, R. Ballarini, J. Mater. Res. 24 (2009) 898-906.

[3] I.W. Chen, Y.H. Chiao, Acta Metall. 31 (1983) 1627-1638.

[4] H.W. Green, P.C. Burnley, Nature 341 (1989) 733-737.

[5] T. Suzuki, T. Tokuoka, I. Yonenaga, H.O.K. Kirchner, Scripta Mater. 43 (2000) 645-650.

[6] P. Gumbsch, S. Taeri-Baghbandari, D. Brunner, W. Sigle, M. Ruhle, Phys. Rev. Lett. 87 (2001) 085505.

[7] T.T. Zhu, A.J. Bushby, D.J. Dunnstan, J. Mech, Phys. Solids 56 (2008) 1170-1185.

[8] R.Z. Valiev, Y. Estrin, Z. Horita, T.G. Langdon, M.J. Zehetbauer, Y.T. Zhu, JOM 58 (4) (2006) 33-39.

[9] P.W. Bridgman, Phys. Rev. 48 (1935) 825-847.

[10] R.Z. Valiev, R.K. Islamgaliev, I.V. Alexandrov, Prog. Mater. Sci. 45 (2000) 103-189.

[11] A.P. Zhilyaev, T.G. Langdon, Prog. Mater. Sci. 53 (2008) 893-979.

[12] S.X. McFadden, R.S. Mishra, R.Z. Valiev, A.P. Zhilyaev, A.K. Mukherjee, Nature 398 (1999) 684-686.

[13] Y.H. Zhao, J.F. Bingert, X.Z. Liao, B.Z. Cui, K. Han, A.V. Sergueeva, A.K. Mukherjee, R.Z. Valiev, T.G. Langdon, Y.T. Zhu, Adv. Mater. 18 (2006) 2949-2953.

[14] M. Kawasaki, R.B. Figueiredo, T.G. Langdon, Acta Mater. 59 (2011) 308-316.

[15] M. Zehetbauer, R. Grossinger, H. Krenn, M. Krystian, R. Pippan, P. Rogl, T. Waitz, R. Wurschum, Adv. Eng. Mater. 12 (2010) 692-700.

[16] R.K. Islamgaliev, R. Kuzel, S.N. Mikov, A.V. Igo, J. Burianek, F. Chmelik, R.Z. Valiev, Mater. Sci. Eng. A 266 (1999) 205-210.

[17] K. Edalati, Z. Horita, Scripta Mater. 64 (2011) 161-164.

[18] J.Y. Huang, Y.T. Zhu, X.Z. Liao, R.Z. Valiev, Phil. Mag. Lett. 84 (2004) 183-190.

[19] C. Mangler, C. Gammer, H.P. Karnthaler, C. Rentenberger, Acta Mater. 58 (2010) 5631-5638.

[20] A.R. Yavari, W.J. Botta, C.A.D. Rodrigues, C. Cardoso, R.Z. Valiev, Scripta Mater. 46 (2002) 711-716.

[21] J. Sort, D.C. Ile, A.P. Zhilyaev, A. Concustell, T. Czeppe, M. Stoica, S. Surinach, J. Eckert, M.D. Baro, Scripta Mater. 50 (2004) 1221-1225.

[22] K. Edalati, Z. Horita, Scripta Mater. 63 (2010) 174-177.

[23] A.R. Kilmametov, A.V. Khristoforova, G. Wilde, R.Z. Valiev, Z. Kristallogr. Suppl. 26 (2007) 339-344.

[24] K. Edalati, E. Matsubara, Z. Horita, Metall. Mater. Trans. A 40 (2009) 2079-2086. 
[25] M.T. Perez-Prado, A.A. Gimazov, O.A. Ruano, M.E. Kassner, A.P. Zhilyaev, Scripta Mater. 58 (2008) 219-222.

[26] K. Edalati, Z. Horita, S. Yagi, E. Matsubara, Mater. Sci. Eng. A 523 (2009) 277-281.

[27] R.C. Garvie, R.H.J. Hannink, R.T. Pascoe, Nature 258 (1975) 703-704.

[28] R.H.J. Hannink, P.M. Kelly, B.C. Muddle, J. Am. Ceram. Soc. 83 (2000) 461-487.

[29] J.M. Leger, P.E. Tomaszewski, A. Atouf, A.S. Pereira, Phys. Rev. B 47 (1993) 14075-14083.

[30] D.M. Stump, Phil. Mag. A 64 (1991) 879-902.

[31] B. Budiansky, L. Truskiovsky, J. Mech, Phys. Solids 41 (1993) 1445-1459.

[32] J.A. Munoz Tabares, M.J. Anglada, J. Am. Ceram. Soc. 93 (2010) 1790-1795.

[33] H. Toraya, M. Yoshimura, S. Somiya, J. Am. Ceram. Soc. 67 (1984) C119-C121.

[34] C. Xu, Z. Horita, T.G. Langdon, Acta Mater. 55 (2007) 203-212.

[35] R. Pippan, S. Scheriau, A. Taylor, M. Hafok, A. Hohenwarter, A. Bachmaier, Annu. Rev. Mater. Res. 40 (2010) 319-343.

[36] Y. Mine, T. Tsumagari, Z. Horita, Scripta Mater. 63 (2010) 552-555.

[37] A.G. Evans, N. Burlingame, M. Drory, W.M. Kriven, Acta Metall. 29 (1981) 447-456 